\title{
Cathepsin B-cleavable doxorubicin prodrugs for targeted cancer therapy (Review)
}

\author{
YAN-JUN ZHONG ${ }^{1,2}$, LI-HUA SHAO ${ }^{1,2}$ and YAN LI $^{1,2}$ \\ ${ }^{1}$ Department of Oncology, Zhongnan Hospital of Wuhan University; ${ }^{2}$ Hubei Key Laboratory of Tumor \\ Biological Behaviors and Hubei Cancer Clinical Study Center, Wuhan 430071, P.R. China
}

Received October 25, 2012; Accepted December 3, 2012

DOI: 10.3892/ijo.2012.1754

\begin{abstract}
Doxorubicin (DOX) is one of the most effective cytotoxic anticancer drugs used for the treatment of hematological malignancies, as well as a broad range of solid tumors. However, the clinical applications of this drug have long been limited due to its severe dose-dependent toxicities. Therefore, DOX derivatives and analogs have been developed to address this issue. A type of DOX prodrug, cleaved by cathepsin B (Cat B), which is highly upregulated in malignant tumors and premalignant lesions, has been developed to achieve a higher DOX concentration in tumor tissue and a lower concentration in normal tissue, so as to enhance the efficacy and reduce toxicity to normal cells. In this review, we focused on Cat B-cleavable DOX prodrugs and discussed the efficacy of these prodrugs, demonstrated by preclinical and clinical developments.
\end{abstract}

Correspondence to: Professor Yan Li, Department of Oncology, Zhongnan Hospital of Wuhan University, 169 Donghu road, Wuhan 430071, P.R. China

E-mail: liyansd2@163.com

Abbreviations: Cat B, cathepsin B; DOX, doxorubicin; HPMA, N-(2-hydroxypropyl)methacrylamide; PK1, HPMA copolymer-GlyPhe-Leu-Gly-doxorubicin; PK2, galactosamine-targeted poly(HPMA)doxorubicin; P-DOX, HPMA copolymer-doxorubicin conjugates; P-(GFLG)-DOX-Ab, HPMA copolymer-DOX-OV-TL16; P-(GFLG)DOX-GalN, HPMA copolymer-Gly-Phe-Lys-Gly-DOX-N-acylated galactosamine; P-(GFLG-DOX)-lac, lactose-containing HPMA copolymer-doxorubicin conjugate; P-(GFLG-DOX)-TriGal, trivalent galactose-containing HPMA copolymer-doxorubicin conjugate; Ma-GFLG-DOX, (N-methacryloyl-glycyl)-dl-phenylalanyl-leucylglycyl-DOX; D2-GFLG-P-DOX, PAMAM dendrimers (D-NH2)Gly-Phe-Leu-Gly-HPMA-doxorubicin; EMC-Arg-Arg-Ala-Leu-AlaLeu-DOX, 6-maleimidocaproic acid-Arg-Arg-Ala-Leu-Ala-LeuDOX; EMC-Phe-Lys-PABC-DOX, $\varepsilon$-maleimidocaproic acid-PheLys-PABC-DOX; PG-Phe-Lys-DOX, hyperbranched polyglycerolPhe-Lys-DOX; Z-Phe-Lys-PABC-DOX, benzyloxycarbonyl-PheLys-PABC-DOX

Key words: cancer chemotherapy, cathepsin B, doxorubicin, prodrugs, targeted therapy

\section{Contents}

1. Introduction

2. Prodrug strategies in cancer treatment

3. Cathepsin B (Cat B) as a prodrug-activating enzyme

4. Cat B-cleavable DOX prodrugs

5. Conclusions

\section{Introduction}

Chemotherapy is a major therapeutic approach for the treatment of cancer. Doxorubicin (DOX; Fig. 1), an anthracycline isolated from Streptomyces strains, is one of the most effective anticancer drugs used for the treatment of hematological malignancies and a broad range of solid tumors, including lymphoma, Kaposi's sarcoma, bone tumors, as well as stomach, breast and ovarian cancers $(1,2)$. DOX in its salt form is readily distributed into almost all tissues and intracellular compartments via passive diffusion or active transport following intravenous administration, resulting in indiscriminative toxic effects on all cells exposed to it. Therefore, the clinical application of DOX is limited by its dose-dependent side-effects, such as bone marrow toxicity, cardiotoxicity, nephrotoxicity and hepatotoxicity.

To reduce the side-effects of this drug, significant efforts have been made to develop DOX derivatives and analogs with less toxic effects and improved pharmacological properties. Several strategies have been investigated in clinical and preclinical trials, including various methods of administration, combinations with other chemotherapeutic drugs [e.g., adriamycin, bleomycin, vinblastine and dacarbazine (ABVD), cyclophosphamide, hydroxydaunomycin, oncovin and prednisone (CHOP)] (3), the addition of antioxidant nutrients (4) and cardioprotectors (5-7), the development of liposomes (8) and nanoparticles (9), the effects of acute exercise (10) and the development of prodrugs (11-13). In this review, we focused on the DOX prodrug strategies.

\section{Prodrug strategies in cancer treatment}

Prodrugs are derivatives of drugs which remain inactive in their prototype form but are metabolized in the body to generate the active drugs at the site of action. They are particularly useful in the development of novel antitumor chemotherapeutic drugs, 


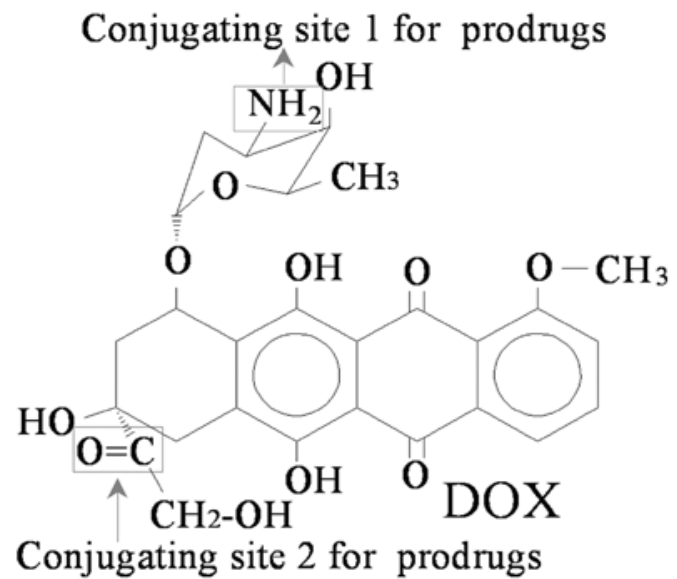

Figure 1. Sructure of DOX. DOX contains an amino group $\left(-\mathrm{NH}_{2}\right)$ on the sixmembered ring, which can conjugate with a carboxyl group $(-\mathrm{COOH})$, and a carbonyl group $(-\mathrm{C}=\mathrm{O})$ on another six-membered ring which can react with amino groups. These are the two most common conjugating sites for prodrug design.

leading to reduced toxicity, improved specificity and the avoidance of multidrug resistance $(14,15)$. The use of prodrugs for targeted therapy is usually based on tumor-associated cell surface markers, such as antigens or receptors, whose expression differs between normal and cancer cells $(16,17)$. Several prodrug strategies have been pursued, including active and passive targeting approaches with antibodies, serum proteins, liposomes and synthetic polymers (18-22). There have been some classic and clinically successful prodrugs, such as capecitabine, an enzyme-activated prodrug, which is converted into 5-fluorouridine or 5-fluoro-2-deoxyuridine in tumor cells to achieve targeted cytotoxicity (23).

Prodrugs can be divided into high- and low-molecular weight drugs in terms of molecular weight (Mw). The former are internalized by passive or active endocytosis and ultimately become localized in the lysosomal components of cells, while the latter usually enter cells mainly by diffusion (24). The Mw and biodistribution of drugs have important impacts on antitumor efficacy. Macromolecular drugs accumulate in tumor tissues due to the enhanced permeability and retention effect (25-27). A Mw below the renal threshold ( $\sim 50,000 \mathrm{~g} /$ mol) is rapidly lost from the circulation; therefore, macromolecular weight drugs may have increased intravascular half-lives, resulting in an increased therapeutic efficacy (27). $\mathrm{N}$-(2-hydroxypropyl) methacrylamide (HPMA), known as one of the most widely used prototypic polymeric drug carriers, was first used to synthesize polymeric drugs in the 1970s, due to its non-immunogenic and non-toxic properties and long circulating half-life $(28,29)$. It has been demonstrated that an HPMA-copolymer Mw of 200,000 to $600,000 \mathrm{~g} / \mathrm{mol}$ is desirable for the efficient passive targeting of solid tumors (30). Prodrugs bearing HPMA have been developed in preclinical studies and include caplostatin $(31,32)$, P-GDM $(33,34)$ and P-HYD-IgG (35), as well as in phase I/II clinical studies and included HPMA copolymer-Gly-Phe-Leu-Gly-doxorubicin (PK1) (36-39), galactosamine-targeted poly(HPMA)doxorubicin (PK2) (40-42), PK3 (36), PNU166945 (43), AP5346 (44-48) and AP5280 (49-51).

\section{Cathepsin B (Cat B) as a prodrug-activating enzyme}

Some tumor-associated enzymes, such as proteases, glucuronidases or carboxylesterases, expressed intra- or extracellularly in cancer cells, can release or activate prodrugs. Cat B, a lysosomal cysteine protease in normal cells and tissues, is considered to be one of the best examples of intracellular proteases. It is highly upregulated in malignant tumors and premalignant lesions at the mRNA and protein levels (52). Cat B is localized in perinuclear vesicles, presumably lysosomes in normal cells. However, in tumor cells and oncogene-transformed cells, Cat $\mathrm{B}$ is localized in perinuclear vesicles and vesicles throughout the cytoplasm and at the cell periphery (53). Pericellular Cat B participates in degrading processes associated with tumor proliferation, invasion and metastasis. Moreover, exposure to DOX can induce a time- and dose-dependent upregulation of Cat B expression at the mRNA and protein levels (5).

Cat B cleaves Leu, Arg-Arg, Ala-Leu, Phe-Arg, Phe-Lys, Ala-Phe-Lys, Gly-Leu-Phe-Gly, Gly-Phe-Leu-Gly and Ala-LeuAla-Leu (18,54-58). There are several low- and high-Mw DOX prodrugs that can be activated by Cat B. Furthermore, DOX immunoconjugates, in which DOX is linked to a carcinomaspecific antibody through Cat B-cleavable oligopeptides, have also been designed (59). All of these conjugates have shown rapid and almost quantitative DOX release in the presence of Cat B. The rate of DOX release depends on the length and structure of the spacer. The tetrapeptide, Gly-Phe-Leu-Gly, has been found to be one of the most suitable spacers. In this regard, the steric interaction between the peptide substrate and Cat B has a significant impact on the release of DOX from prodrugs (60). Therefore, to decrease the steric interaction, it is necessary to integrate a self-immolative spacer, such as para-aminobenzyloxycarbonyl (PABC) between the drug and the oligopeptide substrate.

\section{Cat B-cleavable DOX prodrugs}

Examples of Cat B-cleavable DOX prodrugs are illustrated in Fig. 2 and summarized in Table I.

DOX prodrugs containing the tetrapeptide Gly-Phe-Leu-Gly. The tetrapeptide, Gly-Phe-Leu-Gly, has been proven to be the most effective with respect to both plasma stability and rapid hydrolysis in the presence of Cat B. Therefore, many DOX prodrugs are based on this tetrapeptide.

PK1. PK1 [FCE28068; P(GFLG)-ADR; DOX-HPMA; doxorubicin-HPMA copolymer conjugate; HPMA-doxorubicin, $8 \mathrm{wt} \%$ DOX; Fig. 3A], a polymeric prodrug of $\mathrm{Mw} \sim 30,000 \mathrm{~g} / \mathrm{mol}$, was the first macromolecular prodrug to enter clinical trials, and has reached phase II clinical trials.

Preclinical studies using tumor cells, including L1210 leukemia (61-64), A2780 and DOX-resistant A2780/AD ovarian carcinoma cells, have shown that PK1 can partially avoid the ATP-driven P-glycoprotein (Pgp) efflux pump compared with free DOX (65-67). The $\mathrm{IC}_{50}$ doses of free DOX and PK1 account for the differences in the mechanisms of cellular uptake (65). In preclinical studies using animal models, including B16F10 melanoma, L1210 leukemia, M5076, LS174T human colorectal xenografts (64) and sensitive and resistant human ovarian carcinoma models (68), PK1 has shown enhanced efficacy. 
Table I. List of Cat B-cleavable DOX prodrugs.

\begin{tabular}{|c|c|c|c|c|c|c|}
\hline Name & $\begin{array}{l}\text { Biodegradable } \\
\text { spacer }\end{array}$ & $\begin{array}{c}\mathrm{Mw} \\
(\mathrm{g} / \mathrm{mol})\end{array}$ & $\begin{array}{c}\mathrm{DOX} \\
\text { proportion }\end{array}$ & $\begin{array}{l}\text { Current } \\
\text { status }\end{array}$ & MTD & Refs. \\
\hline DOX & None & 543.5 & $100 \%$ & $\begin{array}{l}\text { Clinical } \\
\text { therapy }\end{array}$ & $60-80 \mathrm{mg} / \mathrm{m}^{2}$ & (69) \\
\hline PK1 & Gly-Phe-Leu-Gly & 30,000 & $8(w t \%)$ & Phase II & $320 \mathrm{mg} / \mathrm{m}^{2}$ & $\begin{array}{l}(36,38,39, \\
61-71)\end{array}$ \\
\hline PK2 & Gly-Phe-Leu-Gly & 27,000 & $8(w t \%)$ & Phase I/II & $160 \mathrm{mg} / \mathrm{m}^{2}$ & $\begin{array}{l}(10,11,40 \\
41,72-76)\end{array}$ \\
\hline P-DOX & Gly-Phe-Leu-Gly & $22,000-1,230,000$ & NA & Preclinical & ND & $26,77,78$ \\
\hline P-(GFLG)-DOX-Ab & Gly-Phe-Leu-Gly & 270,000 & $3.3(\mathrm{wt} \%)$ & Preclinical & ND & $(59,79-81)$ \\
\hline P-(GFLG-DOX)-GalN & Gly-Phe-Leu-Gly & $25,000 / 46,000$ & $5.6 / 1.5(\mathrm{wt} \%)$ & Preclinical & ND & $(59,82,90)$ \\
\hline P-(GFLG-DOX)-Lac & Gly-Phe-Leu-Gly & $20,000-32,000$ & $1.4 \mathrm{~mol} \%$ & Preclinical & ND & $(90)$ \\
\hline P-(GFLG-DOX)-TriGal & Gly-Phe-Leu-Gly & $20,000-32,000$ & $2.1 \mathrm{~mol} \%$ & Preclinical & ND & (90) \\
\hline Ma-GFLG-DOX & Gly-Phe-Leu-Gly & NA & NA & Preclinical & ND & $(91,92)$ \\
\hline D2-GFLG-P(DOX $\left.{ }^{\mathrm{H}}\right)$ & Gly-Phe-Leu-Gly & 215,000 & $9.2(\mathrm{wt} \%)$ & Preclinical & ND & $(91,93)$ \\
\hline HMW1D & Gly-Phe-Leu-Gly & 115,000 & $7.4(w t \%)$ & Preclinical & ND & (93) \\
\hline TET1D & Gly-Phe-Leu-Gly & 19,600 & $10.5(\mathrm{wt} \%)$ & Preclinical & ND & (93) \\
\hline $\begin{array}{l}\text { EMC-Arg-Arg-Ala-Leu-Ala- } \\
\text { Leu-DOX }\end{array}$ & Ala-Leu-Ala-Leu & NA & NA & Preclinical & ND & $(94-96)$ \\
\hline Ac-Phe-Lys-PABC-DOX & Phe-Lys & 1045.5 & $52.0(\mathrm{wt} \%)$ & Preclinical & ND & (12) \\
\hline EMC-Phe-Lys-PABC-DOX & Phe-Lys & 1133 & $50.0(\mathrm{wt} \%)$ & Preclinical & ND & $(2,18,104)$ \\
\hline PG-Phe-Lys-DOX & Phe-Lys & 1207.8 & $45.0(\mathrm{wt} \%)$ & Preclinical & ND & $(18,41,105)$ \\
\hline Z-Phe-Lys-PABC-DOX & Phe-Lys & 1074.0 & $50.6(\mathrm{wt} \%)$ & Preclinical & ND & $(104)$ \\
\hline $\begin{array}{l}\text { BR96-SC-Phe-Lys } \\
\text {-PABC-DOX }\end{array}$ & Phe-Lys & NA & NA & Preclinical & ND & (104) \\
\hline
\end{tabular}

Mw, molecular weight; DOX, doxorubicin; MTD, maximum tolerated dose; NA, not available; ND, not done.

The release of DOX from PK1 in vitro and in vivo using HPLC analysis has shown only a single peak, representing DOX (64). PK1 does not release DOX in the plasma and the covalently-bound drug is biologically inactive following intravenous administration.

Phase I clinical studies on patients with solid tumors, including colorectal, breast, biliary tract, pancreatic, urinary tract, head/neck, non-small cell lung (NSCL), mesothelioma and stomach cancers, have shown that the maximum tolerated dose (MTD) for PK1 is $320 \mathrm{mg} / \mathrm{m}^{2}$, which is 4- to 5-fold higher than the usual clinical dose of free DOX (60-80 $\left.\mathrm{mg} / \mathrm{m}^{2}\right)(69)$. PK1 decreases non-specific organ toxicities by several folds and allows the active drug to be delivered intracellularly, while maintaining antitumor activity $(36,39)$. Phase II studies using PK1 have shown decreased toxicity with evident activity in breast, NSCL and colorectal cancers. Furthermore, SPECT and $\gamma$-camera imaging with ${ }^{123}$ I-labelled drugs have shown obvious tumor accumulation in two metastatic breast cancers (38). PK1 and free DOX greatly differ in their antiproliferative effects and cell death signals in EL-4 cancer cells; treatment with free DOX greatly increases $\mathrm{p} 38$ phosphorylation, while PK1 increases it only slightly; PK1 also significantly increases ERK phosphorylation, while free DOX slightly decreases it (70).
In addition, polymer-directed enzyme prodrug therapy (PDEPT) combining HPMA copolymer-Cat B and PK1 has shown activity against a COR-L23 xenograft, whereas PK1 alone has not and in B16F10 melanoma tumors PDEPT has been shown to more effective than either PK1 or free DOX alone (71).

PK2. PK2 (FCE28069, 27,000 g/mol, 8 wt\% DOX; Fig. 3B), the only targeted polymer conjugate containing galactosamine to enter clinical trials, is designed to target the asialoglycoprotein receptor (ASGPR) which is selectively expressed in hepatocytes and hepatoma cell lines $(40,72)$. Pharmacokinetic studies using PK2 in rats and mice have shown effective liver targeting with $>70 \%$ of the released DOX being selectively targeted to the liver following intravenous administration $(73,74)$. Preclinical studies using rats have demonstrated that PK2 displays a $\sim 5$-fold reduction in cardiotoxicity as opposed to free DOX following intravenous or intraperitoneal administration at various doses $(11,64)$. Furthermore, antitumor activity has been shown to be improved in rodent tumor models (69).

In a pivotal study on a patient with multifocal hepatocellular carcinoma, HPLC and ${ }^{123}$ I-based imaging showed the biphasic clearance of PK2 from the plasma (half-life, $78 \pm 1$ and $990 \pm 15 \mathrm{~min}$ ) and $\sim 30 \%$ of the delivered drug accumulated in 


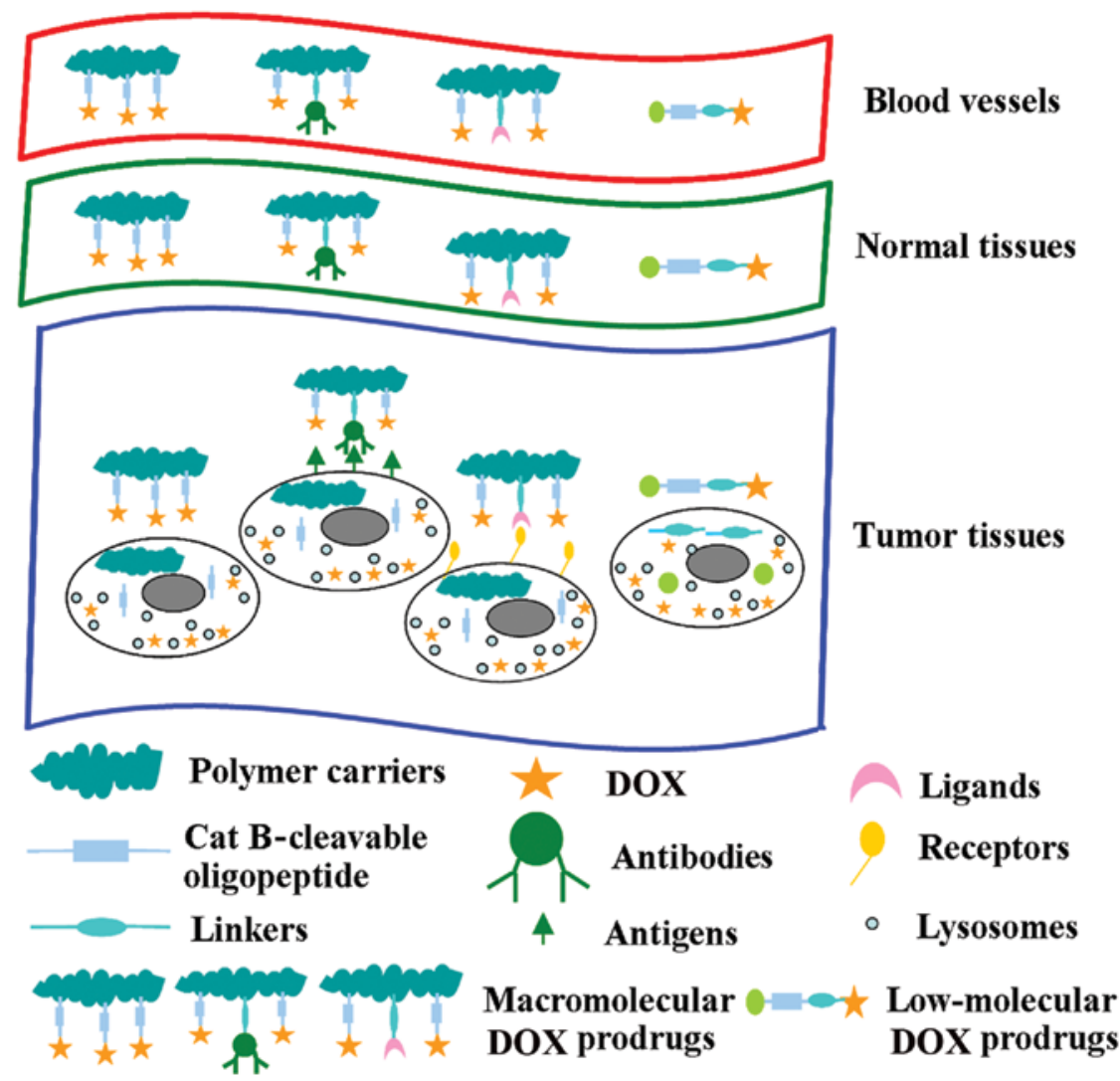

Figure 2. Examples of DOX prodrugs. Macromolecular DOX prodrugs are conjugated with polymer carriers, oligopeptides, with or without antibodies, which can combine with antigens located on the tumor cell surface and ligands that can be recognized by receptors on the tumor cell surface. Low molecular weight DOX prodrugs are combined with oligopeptides, with or without antibodies and ligands. DOX prodrugs remain inactive in blood vessels and normal tissues, but are cleaved by Cat B in tumor tissues and tumor cells, releasing free DOX, which results in targeted cytotoxicity. DOX, doxorubicin; Cat B, cathepsin B.

the liver at $24 \mathrm{~h}$. Moreover, SPECT analysis showed that the radioactivity concentration was 3 - to 4 -fold higher in peritumoral liver tissue than in the tumor tissue itself (40).

Phase I/II trials have shown that the MTD of PK2 is $160 \mathrm{mg} / \mathrm{m}^{2}$ (DOX equivalent) and several hepatocellular carcinoma patients have displayed partial responses and/or stable disease (41). $\gamma$-camera imaging and CT scanning have revealed that $15-20 \%$ of total PK2 is retained in the liver and is mostly concentrated in normal liver tissue (normal versus tumor tissue, 5:1), suggesting that the galactosamine-targeted polymer is mainly delivered to normal regions of the liver due to the increased ASGPR expression in the normal liver (75) and the phagocytosis by Kupffer cells with 'galactose particle' receptor expression (76). Despite this disparity in PK2 distribution, the drug concentration in tumor tissue was still 12- to 50-fold higher than it would have been with the administration of free DOX alone.

HPMA copolymer-doxorubicin conjugates (P-DOX). P-DOX conjugates (Fig. 3C) (77,78) contain the oligopeptide Gly-Phe-Leu-Gly and the $\mathrm{N}^{2}, \mathrm{~N}^{5}$-bis(N-methacryloyl-glycylphenylalanyl-leucyl-glycyl) ornithine cross-linker, which permits the synthesis of P-DOX conjugates with various Mws, from 22 to $1230 \mathrm{kDa}$. The clearance rate of P-DOX from the blood is Mw-dependent and is much slower than that of free DOX $(26,77)$. The therapeutic efficacy has been shown to increase as the Mw of P-DOX increases in nude mice bearing subcutaneous OVCAR-3 xenografts. The low residual concen- tration of P-DOX in tissues (apart from tumors) helps to avoid potential long-term side-effects (77). The toxicity against hematopoietic precursors and normal lymphocytes of inbred mice is considerably decreased (78).

HPMA copolymer-DOX-OV-TL16 [P-(GFLG)-DOX-Ab]. P-(GFLG)-DOX-Ab $(270,000 \mathrm{~g} / \mathrm{mol}, 3.3 \mathrm{wt} \%$ DOX; Fig. 4A) is recognized by the OA3 antigen, which plays a role in membrane transport and/or signal transduction for its multimembranespanning domain structure (59,79-81). The P-(GFLG)-DOX-Ab is rapidly absorbed by OVCAR-3 cells and transported into their lysosomal compartment. DOX is subsequently released from the conjugate at the site with a degradable GFLG spacer, diffused via the lysosomal membrane and accumulates in the cell nuclei (80). Preliminary data on the relative retention of DOX in MDR (A2780/AD) cells have indicated a higher intracellular DOX concentration after incubation with HPMA copolymer-DOX conjugate compared with free DOX (59).

HPMA copolymer-Gly-Phe-Lys-Gly-DOX-N-acylated galactosamine [P-(GFLG)-DOX-GalN]. P-(GFLG)-DOXGalN (25,000 g/mol; Fig. 4B), contains N-acylated galactosamine (GalN), which was designed to be recognized by ASGPR in HepG2 human hepatocellular carcinoma cells $(59,82)$ and individual members of the galectin family (e.g., galectin-3) in human colon adenocarcinoma $(83,84)$. Galectin-3 is expressed in normal tissues and highly expressed in neoplastic tissues (85-87); although the exact opposite has been shown to occur $(88,89)$. In SW-480 and SW-620 cells, the presence of 


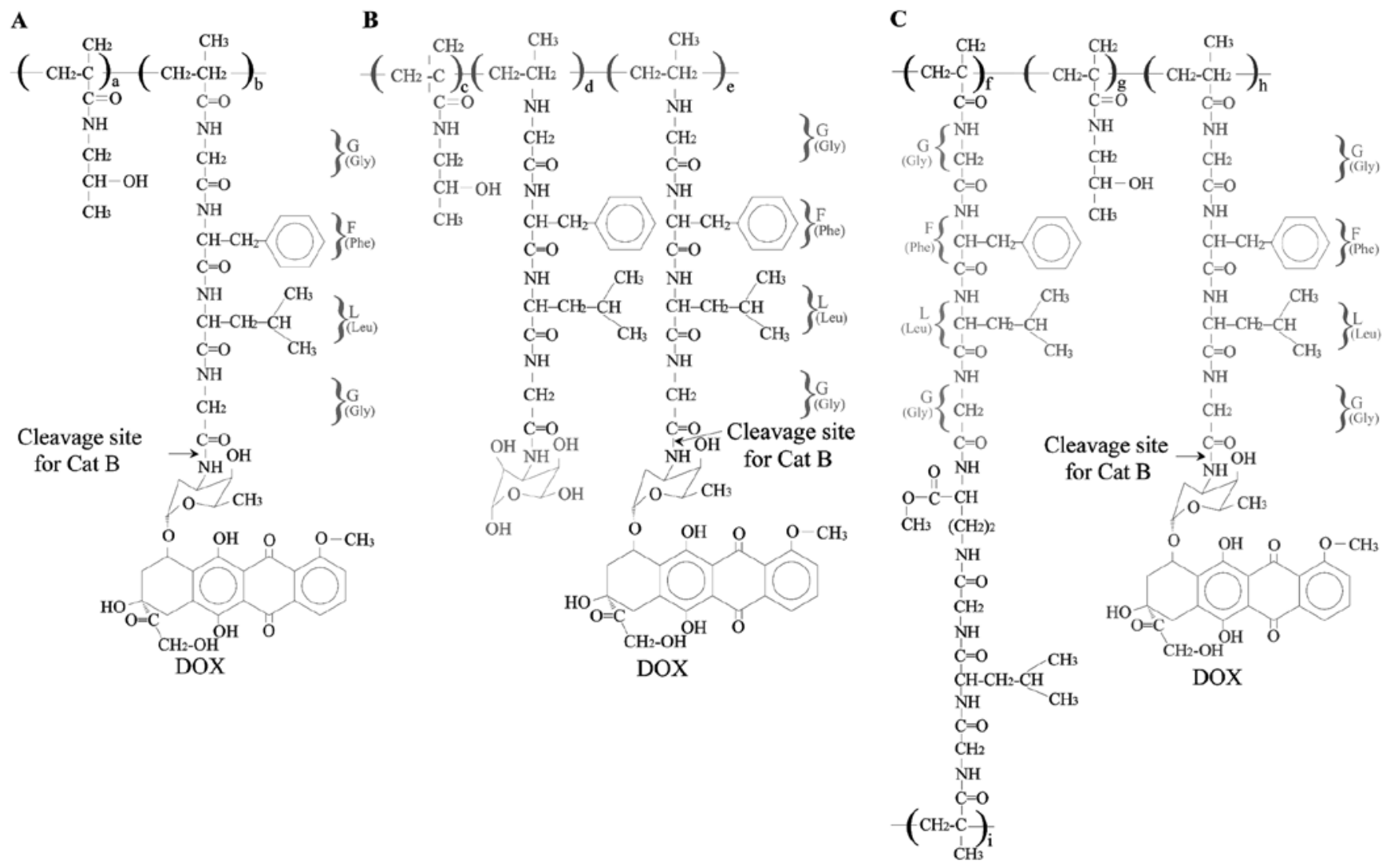

Figure 3. General chemical structures of (A) PK1, (B) PK2 and (C) P-DOX, in which DOX is complexed with (2-hydroxypropyl) methacrylamide (HPMA), by the tetrapeptide linker, Gly-Phe-Leu-Gly (GFLG).

\section{R}

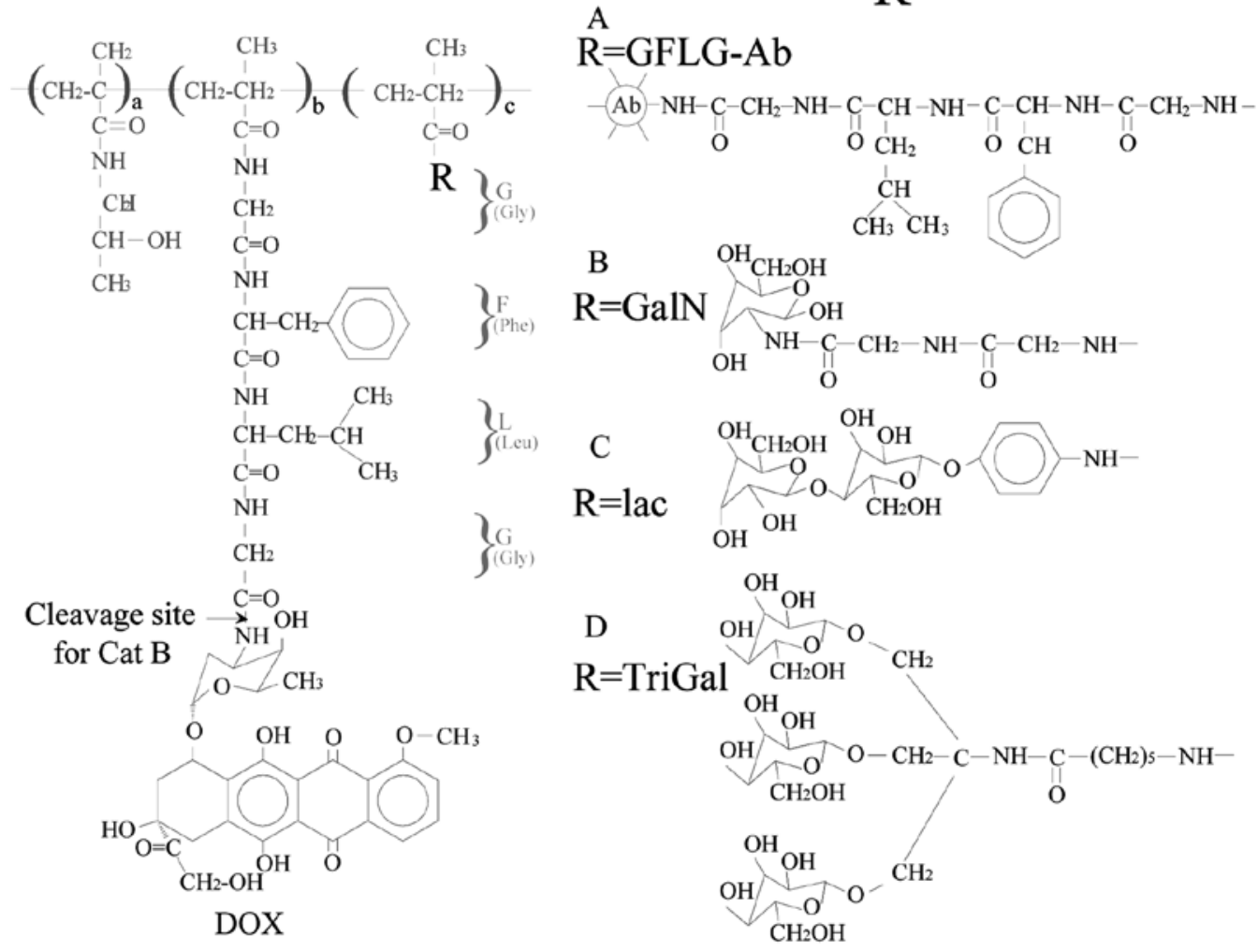

Figure 4. General chemical structures of (A) P-(GFLG)-DOX-Ab, (B) P-(GFLG)-DOX-GalN, (C) P-(GFLG)-DOX-lac and (D) P-(GFLG)-DOX-TriGal, in which DOX is conjugated with HPMA, by the tetrapeptide linker, Gly-Phe-Leu-Gly (GFLG). 


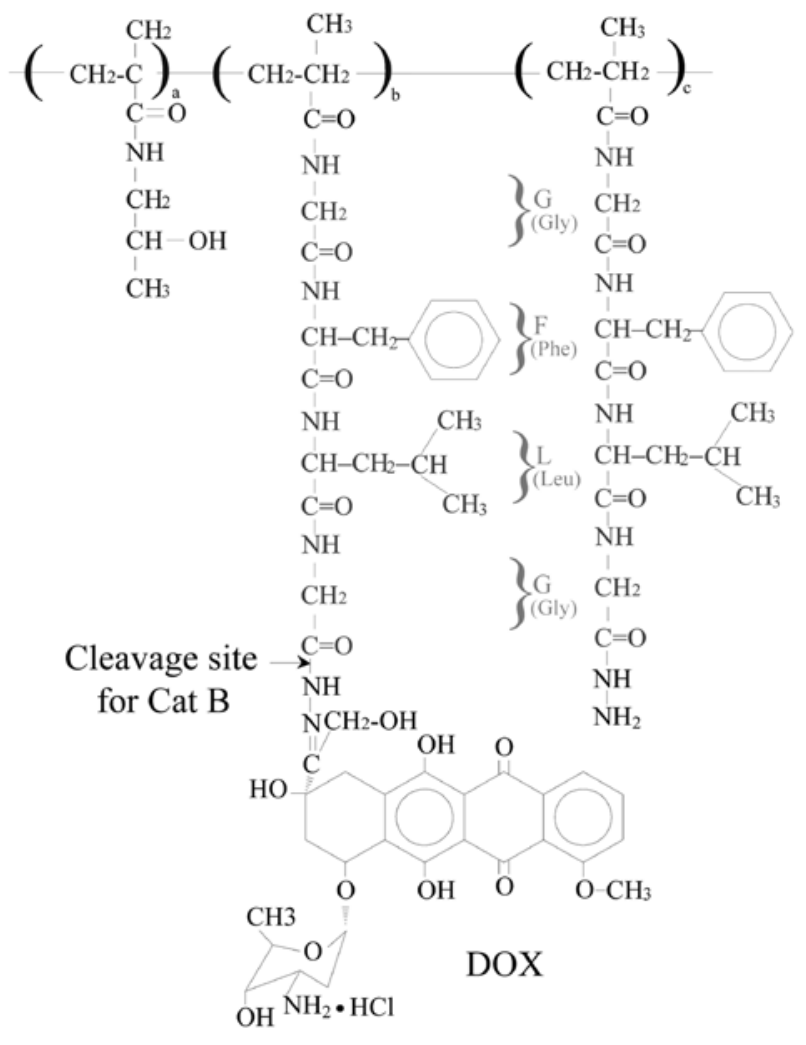

Figure 5. Structure of TET1D, in which DOX is combined with the tetrapeptide, Gly-Phe-Leu-Gly (GFLG).

galectin-3 on the cell surface has been demonstrated by flow cytometry; however, it has not been detected on the surface of Colo-205 cells. The cellular cytotoxicity of P-(GFLG)-DOXGalN determined by MTT assay has been shown to be $\sim 10$-fold higher than P-GFLG-DOX and 10-fold higher in Colo-205 cells than in SW-480 and SW-620 cells (90). This suggests the participation of other galectins, such as galectin- $1,-4,-7$ or -8 , in P-(GFLG)-DOX-GalN targeting.

Lactose-containing HPMA copolymer-doxorubicin conjugate [P-(GFLG-DOX)-lac].P-(GFLG-DOX)-lac (Fig. 4C) (90), can also be biorecognized by galectin-3 on the surface of colon cancer cells. The in vitro cytoxicity determined by MTT assay is higher than that of the non-glycosylated P-(GFLG)-DOX product and almost 1,000-fold lower than that of free DOX in HepG2 human hepatocellular carcinoma cells and Colo-205, SW-480 and SW-620 colon adenocarcinoma cells.

Trivalent galactose-containing HPMA copolymerdoxorubicin conjugate [P-(GFLG-DOX)-TriGal]. P-(GFLG-DOX)-TriGal (Fig. 4D) contains trivalent galactose, which can also be biorecognized by galectin- 3 on the surface of colon adenocarcinoma cells. The cytotoxicity of the P-(GFLGDOX)-TriGal has been shown to be at least 10 -fold higher than that of the non-glycosylated P-(GFLG)-DOX product in Colo-205, SW-480 and SW-620 colon adenocarcinoma cells (90).

$N$-Methacryloyl-glycyl)-dl-phenylalanyl-leucyl-glycyl-DOX (Ma-GFLG-DOX). Ma-GFLG-DOX contains the tetrapeptide, Gly-Phe-Leu-Gly $(91,92)$. It remains quite stable in buffer at $\mathrm{pH} 7.4$ (model of the bloodstream), but releases DOX either under mild acidic conditions or in the presence of Cat B (rich in the tumor microenvironment).
PAMAM dendrimers (D-NH2)-Gly-Phe-Leu-GlyHPMA-doxorubicin (D2-GFLG-P-DOX). D2-GFLG-P-DOX $(215,000 \mathrm{~g} / \mathrm{mol}, 9.2 \mathrm{wt} \% \mathrm{DOX})$, which is attached to DOX via a $\mathrm{pH}$-sensitive hydrazone bond $(91,93)$, was prepared by grafting the semitelechelic HPMA copolymers, which have Mws below the renal threshold, onto a PAMAM dendrimer core via a biodegradable linkage GFLG oligopeptide. An in vitro study using phosphate buffers at $\mathrm{pH} 5.0$ or 7.4 at $37^{\circ} \mathrm{C}$ (hydrazone conjugates) and in a Cat B-containing $\left(5 \times 10^{-7} \mathrm{M}\right)$ phosphate buffer at $37^{\circ} \mathrm{C}$ (amide conjugates) showed that the presence of Cat B increased the rate of DOX release (91).

HMW1D. HMW1D (115,000 g/mol, $7.4 \mathrm{wt} \%$ DOX), a branched polymer prodrug, contains water-soluble polymer drug carriers, HPMA copolymers, and a biodegradable oligopeptide sequence, GFLG, linking shorter polymer chains $(\mathrm{Mw}, 20,000 \mathrm{~g} / \mathrm{mol})$ into a high-Mw structure $(\mathrm{Mw}, 110,000 \mathrm{~g} / \mathrm{mol}$ ) to enhance the passive accumulation of the drug by increasing its $\mathrm{Mw}$. An in vitro study showed that this $\mathrm{pH}$-sensitive prodrug (HMW1D) can be degraded by Cat B $\left(5 \times 10^{-7} \mathrm{M}\right), 37^{\circ} \mathrm{C}, \mathrm{pH} 6.0$ (93).

TET1D. TET1D (19,600 g/mol, 10.5 wt\% DOX; Fig. 5) (93) a non-targeted polymer-bound doxorubicin conjugate, contains a hydrazone bond, which significantly improves the rate of DOX release, compared with that of classical HPMA polymer prodrugs bearing DOX attached via amide bonds limited to maximum 8-9 wt \%. An in vitro study using T-splenocytes and mouse EL-4 T cell lymphoma cells showed that the toxicity of TET1D is much higher compared with that of similar classic conjugates and an in vivo study using EL4 T cell lymphoma mice C57BL/10 showed that the antitumor activity was also significantly increased. An in vitro study showed that TET1D can be cleaved by Cat B; however, Cat B is not essential in the release of DOX, for it also contains a $\mathrm{pH}$-sensitive spacer which is stable under physiological conditions (pH 7.4, e.g., blood) and hydrolytically degradable in a mild acidic environment (pH 5.0, e.g., endosome) (93).

DOX prodrugs containing the tetrapeptide, Ala-Leu-Ala-Leu 6-Maleimidocaproic acid-Arg-Arg-Ala-Leu-Ala-Leu-DOX (EMC-Arg-Arg-Ala-Leu-Ala-Leu-DOX). EMC-Arg-Arg-AlaLeu-Ala-Leu-DOX bears maleimide (94), which can rapidly and selectively react in situ with the cysteine-34 position of circulating albumin after intravenous administration and release the drug at the tumor site $(95,96)$. Albumin is a promising drug carrier due to its passive accumulation in solid tumors, which have a high metabolic turnover, angiogenesis, hypervasculature, defective vascular architecture and impaired lymphatic drainage (97). Albumin has non-toxic, non-immunogenic, biocompatible and biodegradable properties (98) and has demonstrated preferential tumor uptake in various tumor xenograft animal models (99). The antitumor efficacy of EMC-Arg-Arg-Ala-Leu-Ala-Leu-DOX has been shown to be comparable to that of free DOX in a M-3366 breast cancer xenograft model at equivalent doses (94). Moreover, the albumin-binding DOX prodrug, DOX-EMCH (INNO-206), has been examined in clinical trials $(100,101)$.

DOX prodrugs containing the dipeptide, Phe-Lys Ac-Phe-Lys-PABC-DOX. Ac-Phe-Lys-PABC-DOX (PDOX, $1045.5 \mathrm{~g} / \mathrm{mol}, 52.0 \%$ DOX, Fig. 6A) contains the dipeptide, 


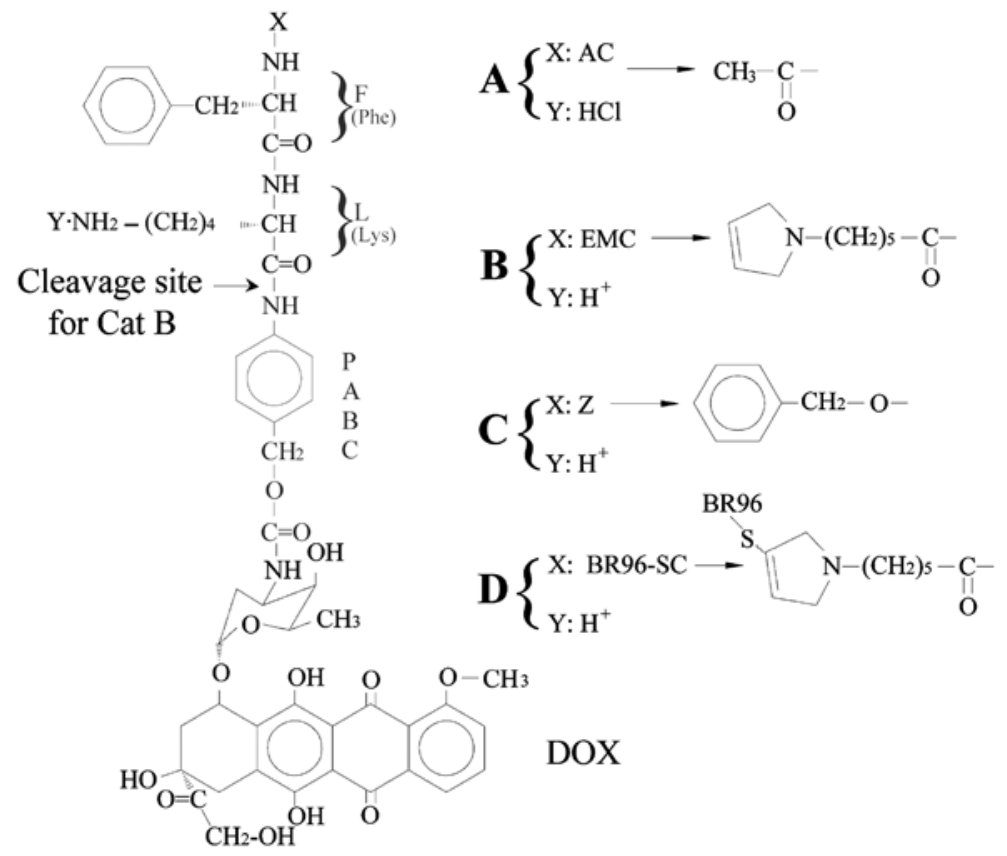

Figure 6. Structure of (A) Ac-Phe-Lys-PABC-DOX, (B) EMC-Phe-Lys-PABC-DOX, (C) Z-Phe-Lys-PABC-DOX and (D) BR96-SC-Phe-Lys-PABC-DOX, in which DOX is linked to the self-immolative spacer, para-aminobenzyloxycarbonyl (PABC) and the dipeptide, Phe-Lys (FL).

A

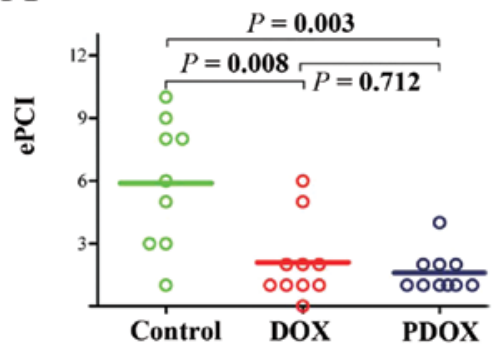

$\mathrm{D}$

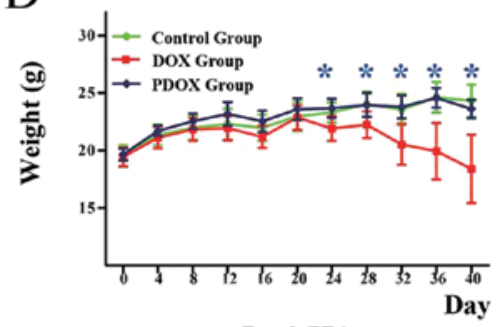

G

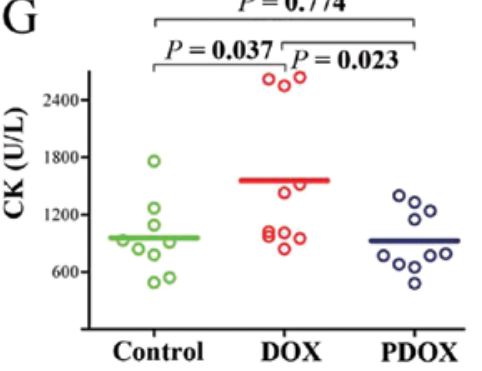

B

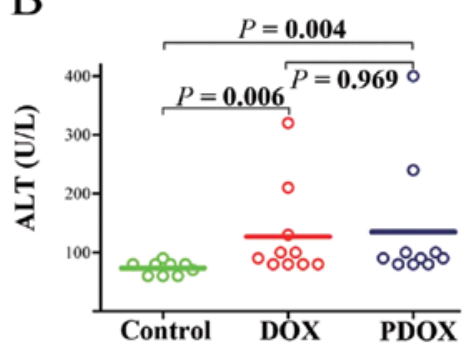

E $\quad \frac{P=0.842}{P=0.037 \stackrel{P=0.064}{P}}$

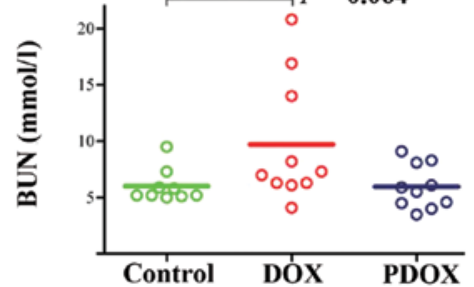

$\mathrm{H}$

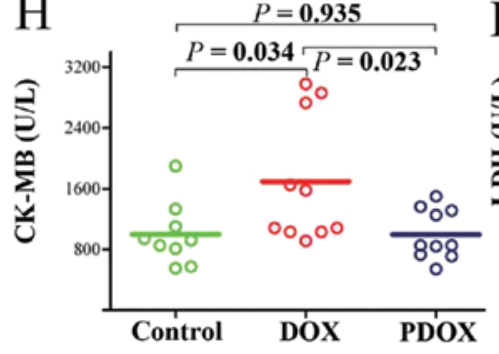

C
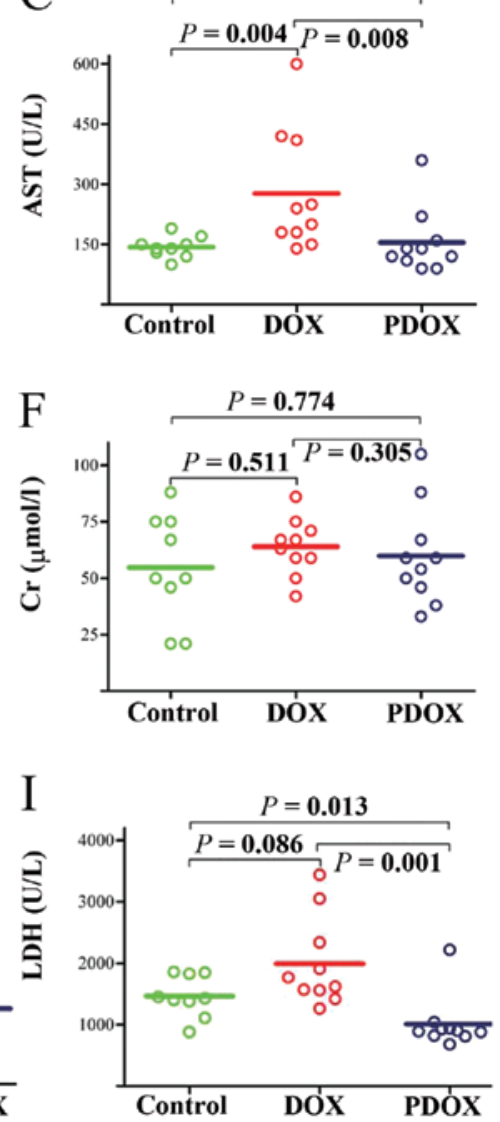

Figure 7. Cat B-cleavable prodrug Ac-Phe-Lys-PABC-DOX (PDOX) enhances treatment efficacy and reduces toxicity in treating gastric cancer with peritoneal carcinomatosis [modified from a previous study (12)]. (A) Effects of DOX and PDOX on a peritoneal carcinomatosis model are shown with the detailed experimental peritoneal carcinomatosis index (ePCI) score; both DOX and PDOX significantly reduced the ePCI. PDOX reduced general toxicity and toxicity to the liver, kidney and the heart in particular. (D) Nude mice in the PDOX group had similar body weights to those in the control group throughout the study period, while nude mice in the DOX group showed a progressive decrease in body weight after 4 doses of intraperitoneal injection. Effects of PDOX and DOX on major liver and renal function parameters are shown in (B) ALT, (C) AST, (E) BUN and (F) Cr. PDOX significantly decreased hepatotoxicity compared with DOX in terms of AST. PDOX significantly decreased myocardial toxicity compared with DOX by reducing (G) CK, (H) CK-MB and (I) LDH. ALT, alanine aminotransferase; AST, aspartate aminotransferase; BUN, blood urea nitrogen; $\mathrm{Cr}$, creatinine; CK, creatine kinase; CK-MB, creatine kinase-MB isoenzyme; $\mathrm{LDH}$, lactate dehydrogenase. 
Phe-Lys, which is specific for Cat B and the self-immolative spacer, PABC (12,102-104). An in vivo study using a nude mice model of gastric cancer with peritoneal carcinomatosis showed that, compared with free DOX, PDOX $(16 \mathrm{mg} / \mathrm{kg}$, twice that of DOX in terms of equal molecular content) produced better antitumor effects in terms of experimental peritoneal carcinomatosis index (ePCI) (Fig. 7A) and body weight (Fig. 7D), and reduced liver (Fig. 7B and C), kidney (Fig. 7E and F) and heart (Fig. 7G-I) toxicities (12).

$\varepsilon$-maleimidocaproic acid-Phe-Lys-PABC-DOX (EMC-Phe-Lys-PABC-DOX). EMC-Phe-Lys-PABC-DOX (Fig. 6B) $(2,18,104)$ has exhibited dramatic differences in antitumor activity between in vitro and in vivo studies. An in vitro cytotoxicity study using the pancreatic tumor cell line, AsPC1 LN, and the melanoma cancer cell line, MDA-MB$231 \mathrm{LN}$, showed that DOX was $\sim 6$-fold more active than the prodrug. However, an in vivo study using a breast cancer xenograft nude mice model of MDA-MB-435 cells showed that the prodrug exhibited superior antitumor activity (tumor size, $15 \%$ of that in nude mice treated with the vehicle) compared to DOX (tumor size, $49 \%$ of that in nude mice treated with the vehicle) in an equitoxic comparison (2).

$P G$-Phe-Lys-DOX. Hyperbranched polyglycerol-Phe-LysDOX (PG-Phe-Lys-DOX, 45\% DOX) $(18,41,105)$, contains the dipeptide, Phe-Lys, and hyperbranched polyglycerol. The drug release of the conjugates suggested an effective cleavage of PG-Phe-Lys-DOX and release of DOX in the presence of Cat $\mathrm{B}$. The $\mathrm{IC}_{50}$ of PG-Phe-Lys-DOX in the breast cancer cell line, MDA-MB-231, and the pancreatic carcinoma cell line, AsPC1, was $1.10 \pm 0.4$ and $2.4 \pm 0.6 \mu \mathrm{M}$, respectively, both of which were lower than that of free DOX (105).

Z-Phe-Lys-PABC-DOX. Benzyloxycarbonyl-Phe-LysPABC-DOX (Z-Phe-Lys-PABC-DOX; Fig. 6C), is stable in human plasma and rapidly releases DOX in the presence of Cat $\mathrm{B}$ at $37^{\circ} \mathrm{C}$, pH 5.0 (half-life, $8 \mathrm{~min}$ ), which is 30 -fold faster than that of the Val-Cit conjugate. On the other hand, the release rate is significantly faster than Z-Phe-Lys-DOX, suggesting that a self immolative spacer, such as PABC, is helpful for DOX release from conjugates (104).

BR96-SC-Phe-Lys-PABC-DOX. BR96-SC-Phe-LysPABC-DOX (Fig. 6D) contains the chimeric monoclonal antibody, BR96, that binds specifically to a Lewis ${ }^{\mathrm{y}}$-related, tumor-associated antigen expressed on the surface of many human carcinoma cells. An in vitro study using human carcinomal cell lines expressing varying levels of the BR96 antigen showed that the cytotoxicity of BR96-Phe-Lys-PABC-DOX was directly related to the level of antigen expression on the cell membrane: the higher level of BR96 antigen, the higher the sensitivity to BR96-Phe-Lys-PABC-DOX. The cytotoxicity of BR96-Phe-Lys-PABC-DOX in high BR96 antigen-expressing cell lines is higher than that of the non-binding IgG-SC-PheLys-PABC-DOX conjugate (>220-fold), confirming its BR96 antigen specificity (104).

Other DOX prodrugs containing dipeptides. Dubowchik et al (104) and de Groot et al (106) synthesized a series of other DOX prodrugs containing the dipeptides, Phe-Lys, Ala-Lys or Phe-Arg, including Z-Phe-Lys-PABC-DOX-HCl, MC-Phe-Lys(MMT)-PABC-DOX, MC-Phe-Lys-PABCDOX $\cdot \mathrm{Cl}_{2} \mathrm{CHCO}_{2} \mathrm{H}, \mathrm{Z}$-Phe-Lys(alloc)-DOX, Z-Phe-Lys-DOX.HCl, Z-Ala-Lys(alloc)-PABC-DOX, Z-Ala-Lys-PABC-DOX. $\mathrm{HCl}$,
Z-Phe-Arg( $\left.\mathrm{NO}_{2}\right)$-PABC-DOX, Z-Phe-Arg(Ts)-PABC-DOX, Fmoc-Phe-Lys(Aloc)-PABC-DOX and H-Phe-Lys(Aloc)PABC-DOX. However, data regarding their antitumor activity are lacking.

\section{Conclusions}

Over the past few decades, significant efforts have been made to develop antitumor prodrugs with increased efficacy and decreased toxicity. Numerous DOX prodrugs have been synthesized by structure modification strategies. Cat B-cleavable DOX prodrugs release the free drugs in the presence of Cat $\mathrm{B}$ and in a subacidic environment. A number of in vitro cancer cell studies and in vivo tumor xenograft studies have demonstrated Cat B-cleavable DOX prodrugs to be less toxic in vitro and more effective in vivo, demonstrating the role of Cat B.

However, there remain many challenges and questions. The majority of the studies mentioned in this review are in a very early preclinical stage with little information on physicochemical properties, cytotoxicity and antitumor efficacy in tumor cells and xenografts. The subcellular distribution of the prodrugs, the free drugs released and the antitumor mechanisms remain unclear. Further studies are warranted and should focus on preclinical and clinical evaluation of existing prodrugs, rather than synthesizing novel drug candidates in this field.

\section{Acknowledgements}

This study was supported by the State Key Research Project on Infectious Diseases (2012ZX10002012-012) and the National Natural Science Foundation of China (no. 81171396) and National University Students Innovation Training Project of China (101048639).

\section{References}

1. Gianni L, Grasselli G, Cresta S, Locatelli A, Vigano L and Minotti G: Anthracyclines. Cancer Chemother Biol Response Modif 21: 29-40, 2003.

2. Abu Ajaj K, Graeser R, Fichtner I and Kratz F: In vitro and in vivo study of an albumin-binding prodrug of doxorubicin that is cleaved by cathepsin B. Cancer Chemother Pharmacol 64: 413-418, 2009.

3. Ogura M: Adriamycin (doxorubicin). Gan To Kagaku Ryoho 28: 1331-1338, 2001 (In Japanese)

4. Granados-Principal S, Quiles JL, Ramirez-Tortosa CL, Sanchez-Rovira P and Ramirez-Tortosa MC: New advances in molecular mechanisms and the prevention of adriamycin toxicity by antioxidant nutrients. Food Chem Toxicol 48: 1425-1438, 2010

5. Herman EH, Ferrans VJ, Jordan W and Ardalan B: Reduction of chronic daunorubicin cardiotoxicity by ICRF-187 in rabbits. Res Commun Chem Pathol Pharmacol 31: 85-97, 1981.

6. Wexler LH, Andrich MP, Venzon D, et al: Randomized trial of the cardioprotective agent ICRF-187 in pediatric sarcoma patients treated with doxorubicin. J Clin Oncol 14: 362-372, 1996.

7. Lipshultz SE: Dexrazoxane for protection against cardiotoxic effects of anthracyclines in children. J Clin Oncol 14: 328-331, 1996.

8. Cattel L, Ceruti M and Dosio F: From conventional to stealth liposomes: a new frontier in cancer chemotherapy. Tumori 89: 237-249, 2003.

9. Li J, Wu C, Dai Y, Zhang R, Wang X, Fu D and Chen B: Doxorubicin-CdS nanoparticles: a potential anticancer agent for enhancing the drug uptake of cancer cells. J Nanosci Nanotechnol 7: 435-439, 2007. 
10. Ascensao A, Lumini-Oliveira J, Machado NG, et al: Acute exercise protects against calcium-induced cardiac mitochondrial permeability transition pore opening in doxorubicin-treated rats. Clin Sci 120: 37-49, 2011.

11. Yeung TK, Hopewell JW, Simmonds RH, et al: Reduced cardiotoxicity of doxorubicin given in the form of $\mathrm{N}$-(2-hydroxypropyl) methacrylamide conjugates: and experimental study in the rat. Cancer Chemother Pharmacol 29: 105-111, 1991.

12. Shao LH, Liu SP, Hou JX, et al: Cathepsin B cleavable novel prodrug Ac-Phe-Lys-PABC-ADM enhances efficacy at reduced toxicity in treating gastric cancer peritoneal carcinomatosis: an experimental study. Cancer 118: 2986-2996, 2011.

13. Kratz F, Warnecke A, Schmid B, Chung DE and Gitzel M: Prodrugs of anthracyclines in cancer chemotherapy. Curr Med Chem 13: 477-523, 2006.

14. Muller MB, Keck ME, Binder EB, et al: ABCB1 (MDR1)-type P-glycoproteins at the blood-brain barrier modulate the activity of the hypothalamic-pituitary-adrenocortical system: implications for affective disorder. Neuropsychopharmacology 28: 1991-1999, 2003

15. Gottesman MM, Fojo T and Bates SE: Multidrug resistance in cancer: role of ATP-dependent transporters. Nat Rev Cancer 2: 48-58, 2002.

16. Lu Y, Yang $\mathrm{J}$ and Sega E: Issues related to targeted delivery of proteins and peptides. AAPS J 8: E466-E478, 2006.

17. Juillerat-Jeanneret L and Schmitt F: Chemical modification of therapeutic drugs or drug vector systems to achieve targeted therapy: looking for the grail. Med Res Rev 27: 574-590, 2007.

18. Calderon M, Graeser R, Kratz F and Haag R: Development of enzymatically cleavable prodrugs derived from dendritic polyglycerol. Bioorg Med Chem Lett 19: 3725-3728, 2009.

19. Haag R and Kratz F: Polymer therapeutics: concepts and applications. Angew Chem Int Ed Engl 45: 1198-1215, 2006.

20. Duncan R: Polymer conjugates as anticancer nanomedicines. Nat Rev Cancer 6: 688-701, 2006.

21. Vicent MJ, Dieudonne L, Carbajo RJ and Pineda-Lucena A: Polymer conjugates as therapeutics: future trends, challenges and opportunities. Expert Opin Drug Deliv 5: 593-614, 2008.

22. Kiick KL: Materials science. Polymer therapeutics. Science 317: 1182-1183, 2007

23. Schilsky RL: Pharmacology and clinical status of capecitabine. Oncology 14: 1297-1306; discussion 1309-1311, 2000.

24. Basu SK: Receptor-mediated endocytosis of macromolecular conjugates in selective drug delivery. Biochem Pharmacol 40: 1941-1946, 1990

25. Noguchi Y, Wu J, Duncan R, Strohalm J, Ulbrich K, Akaike T and Maeda H: Early phase tumor accumulation of macromolecules: a great difference in clearance rate between tumor and normal tissues. Jpn J Cancer Res 89: 307-314, 1998.

26. Shiah JJ, Sun Y, Peterson CM and Kopecek J: Biodistribution of free and $\mathrm{N}$-(2-hydroxypropyl)methacrylamide copolymer-bound mesochlorin e (6) and adriamycin in nude mice bearing human ovarian carcinoma OVCAR-3 xenografts. J Control Release 61: 145-157, 1999.

27. Bogdanov A Jr, Wright SC, Marecos EM, Bogdanova A, Martin C, Petherick P and Weissleder R: A long-circulating co-polymer in 'passive targeting' to solid tumors. J Drug Target 4: 321-330, 1997.

28. Kopecek J, Sprincl L and Lim D: New types of synthetic infusion solutions. I. Investigation of the effect of solutions of some hydrophilic polymers on blood. J Biomed Mater Res 7: 179-191, 1973

29. Sprincl L, Exner J, Sterba O and Kopecek J: New types of synthetic infusion solutions. III. Elimination and retention of poly-[N-(2-hydroxypropyl)methacrylamide] in a test organism. J Biomed Mater Res 10: 953-963, 1976

30. Etrych T, Kovar L, Strohalm J, Chytil P, Rihova B and Ulbrich K Biodegradable star HPMA polymer-drug conjugates: biodegradability, distribution and anti-tumor efficacy. J Control Release 154: 241-248, 2011

31. Satchi-Fainaro R, Puder M, Davies JW, et al: Targeting angiogenesis with a conjugate of HPMA copolymer and TNP-470. Nat Med 10: 255-261, 2004

32. Satchi-Fainaro R, Mamluk R, Wang L, et al: Inhibition of vessel permeability by TNP-470 and its polymer conjugate, caplostatin Cancer Cell 7: 251-261, 2005.

33. Kasuya Y, Lu ZR, Kopeckova P, Minko T, Tabibi SE and Kopecek J: Synthesis and characterization of HPMA copolymeraminopropylgeldanamycin conjugates. J Control Release 74 203-211, 2001
34. Nishiyama N, Nori A, Malugin A, Kasuya Y, Kopeckova P and Kopecek J: Free and N-(2-hydroxypropyl)methacrylamide copolymer-bound geldanamycin derivative induce different stress responses in A2780 human ovarian carcinoma cells. Cancer Res 63: 7876-7882, 2003.

35. Etrych T, Mrkvan T, Rihova B and Ulbrich K: Star-shaped immunoglobulin-containing HPMA-based conjugates with doxorubicin for cancer therapy. J Control Release 122: 31-38, 2007.

36. Vasey PA, Kaye SB, Morrison R, et al: Phase I clinical and pharmacokinetic study of PK1 [N-(2-hydroxypropyl)methacrylamide copolymer doxorubicin]: first member of a new class of chemotherapeutic agents-drug-polymer conjugates. Cancer Research Campaign Phase I/II Committee. Clin Cancer Res 5: 83-94, 1999.

37. Bilim V: Technology evaluation: PK1, Pfizer/Cancer Research UK. Curr Opin Mol Ther 5: 326-330, 2003.

38. Seymour LW, Ferry DR, Kerr DJ, et al: Phase II studies of polymer-doxorubicin (PK1, FCE28068) in the treatment of breast, lung and colorectal cancer. Int J Oncol 34: 1629-1636, 2009.

39. Thomson AH, Vasey PA, Murray LS, Cassidy J, Fraier D, Frigerio E and Twelves C: Population pharmacokinetics in phase I drug development: a phase I study of PK1 in patients with solid tumours. Br J Cancer 81: 99-107, 1999

40. Julyan PJ, Seymour LW, Ferry DR, et al: Preliminary clinical study of the distribution of HPMA copolymers bearing doxorubicin and galactosamine. J Control Release 57: 281-290, 1999.

41. Seymour LW, Ferry DR, Anderson D, et al: Hepatic drug targeting: phase I evaluation of polymer-bound doxorubicin. J Clin Oncol 20: 1668-1676, 2002.

42. Seymour LW, Ulbrich K, Wedge SR, Hume IC, Strohalm J and Duncan R: N-(2-hydroxypropyl)methacrylamide copolymers targeted to the hepatocyte galactose-receptor: pharmacokinetics in DBA2 mice. Br J Cancer 63: 859-866, 1991.

43. Meerum Terwogt JM, ten Bokkel Huinink WW, Schellens JH, et al: Phase I clinical and pharmacokinetic study of PNU166945, a novel water-soluble polymer-conjugated prodrug of paclitaxel. Anticancer Drugs 12: 315-323, 2001

44. Rice JR, Gerberich JL, Nowotnik DP and Howell SB: Preclinical efficacy and pharmacokinetics of AP5346, a novel diaminocyclohexane-platinum tumor-targeting drug delivery system. Clin Cancer Res 12: 2248-2254, 2006.

45. Nowotnik DP and Cvitkovic E: ProLindac (AP5346): a review of the development of an HPMA DACH platinum polymer therapeutic. Adv Drug Deliv Rev 61: 1214-1219, 2009.

46. Campone M, Rademaker-Lakhai JM, Bennouna J, Howell SB Nowotnik DP, Beijnen JH and Schellens JH: Phase I and pharmacokinetic trial of AP5346, a DACH-platinum-polymer conjugate, administered weekly for three out of every 4 weeks to advanced solid tumor patients. Cancer Chemother Pharmacol 60: 523-533, 2007.

47. Van der Schoot SC, Nuijen B, Sood P, Thurmond KB II, Stewart DR, Rice JR and Beijnen JH: Pharmaceutical development, quality control, stability and compatibility of a parenteral lyophilized formulation of the investigational polymer-conjugated platinum antineoplastic agent AP5346. Pharmazie 61: 835-844, 2006

48. Sood P, Thurmond KB II, Jacob JE, Waller LK, Silva GO, Stewart DR and Nowotnik DP: Synthesis and characterization of AP5346, a novel polymer-linked diaminocyclohexyl platinum chemotherapeutic agent. Bioconjug Chem 17: 1270-1279, 2006.

49. Rademaker-Lakhai JM, Terret C, Howell SB, et al: A Phase I and pharmacological study of the platinum polymer AP5280 given as an intravenous infusion once every 3 weeks in patients with solid tumors. Clin Cancer Res 10: 3386-3395, 2004.

50. Tibben MM, Rademaker-Lakhai JM, Rice JR, Stewart DR, Schellens JH and Beijnen JH: Determination of total platinum in plasma and plasma ultrafiltrate, from subjects dosed with the platinum-containing N-(2-hydroxypropyl)methacrylamide copolymer AP5280, by use of graphite-furnace Zeeman atomic-absorption spectrometry. Anal Bioanal Chem 373: 233-236, 2002

51. Lin X, Zhang Q, Rice JR, Stewart DR, Nowotnik DP and Howell SB: Improved targeting of platinum chemotherapeutics. the antitumour activity of the HPMA copolymer platinum agent AP5280 in murine tumour models. Eur J Cancer 40: 291-297, 2004.

52. Podgorski I and Sloane BF: Cathepsin B and its role(s) in cancer progression. Biochem Soc Symp 70: 263-276, 2003. 
53. Calkins CC, Sameni M, Koblinski J, Sloane BF and Moin K Differential localization of cysteine protease inhibitors and a target cysteine protease, cathepsin $\mathrm{B}$, by immuno-confocal microscopy. J Histochem Cytochem 46: 745-751, 1998.

54. Kovar M, Strohalm J, Etrych T, Ulbrich K and Rihova B: Star structure of antibody-targeted HPMA copolymer-bound doxorubicin: a novel type of polymeric conjugate for targeted drug delivery with potent antitumor effect. Bioconjug Chem 13: 206-215, 2002

55. Thanou M and Duncan R: Polymer-protein and polymer-drug conjugates in cancer therapy. Curr Opin Investig Drugs 4: 701-709, 2003

56. Mai J, Waisman DM and Sloane BF: Cell surface complex of cathepsin $\mathrm{B} /$ annexin II tetramer in malignant progression. Biochim Biophys Acta 1477: 215-230, 2000.

57. Kratz F, Muller IA, Ryppa C and Warnecke A: Prodrug strategies in anticancer chemotherapy. Chem MedChem 3: 20-53, 2008.

58. Trouet A, Masquelier M, Baurain R and Deprez-De Campeneere D: A covalent linkage between daunorubicin and proteins that is stable in serum and reversible by lysosomal hydrolases, as required for a lysosomotropic drug-carrier conjugate: in vitro and in vivo studies. Proc Natl Acad Sci USA 79: 626-629, 1982.

59. Omelyanenko V, Kopeckova P, Gentry C and Kopecek J: Targetable HPMA copolymer-adriamycin conjugates Recognition, internalization and subcellular fate. J Control Release 53: 25-37, 1998

60. Carl PL, Chakravarty PK and Katzenellenbogen JA: A novel connector linkage applicable in prodrug design. J Med Chem 24 479-480, 1981.

61. Seymour LW, Ulbrich K, Steyger PS, Brereton M, Subr V, Strohalm J and Duncan R: Tumour tropism and anti-cancer efficacy of polymer-based doxorubicin prodrugs in the treatment of subcutaneous murine B16F10 melanoma. Br J Cancer 70 636-641, 1994.

62. Duncan R, Kopeckova P, Strohalm J, Hume IC, Lloyd JB and Kopecek J: Anticancer agents coupled to N-(2-hydroxypropyl) methacrylamide copolymers. II. Evaluation of daunomycin conjugates in vivo against L1210 leukaemia. Br J Cancer 57: $147-156,1988$

63. Duncan R, Kopeckova-Rejmanova P, Strohalm J, et al: Anticancer agents coupled to $\mathrm{N}$-(2-hydroxypropyl)methacrylamide copolymers. I. Evaluation of daunomycin and puromycin conjugates in vitro. Br J Cancer 55: 165-174, 1987.

64. Hopewel JW, Duncan R, Wilding D and Chakrabarti K Preclinical evaluation of the cardiotoxicity of PK2: a novel HPMA copolymer-doxorubicin-galactosamine conjugate antitumour agent. Hum Exp Toxicol 20: 461-470, 2001.

65. Minko T, Kopeckova P, Pozharov V and Kopecek J: HPMA copolymer bound adriamycin overcomes MDR1 gene encoded resistance in a human ovarian carcinoma cell line. J Contro Release 54: 223-233, 1998

66. Minko T, Kopeckova P and Kopecek J: Chronic exposure to HPMA copolymer-bound adriamycin does not induce multidrug resistance in a human ovarian carcinoma cell line. J Control Release 59: 133-148, 1999.

67. Tijerina M, Fowers KD, Kopeckova $\mathrm{P}$ and Kopecek J: Chronic exposure of human ovarian carcinoma cells to free or HPMA copolymer-bound mesochlorin e6 does not induce $\mathrm{P}$-glycoprotein-mediated multidrug resistance. Biomaterials 21 : 2203-2210, 2000.

68. Minko T, Kopeckova P and Kopecek J: Efficacy of the chemotherapeutic action of HPMA copolymer-bound doxorubicin in a solid tumor model of ovarian carcinoma. Int J Cancer 86 108-117, 2000.

69. Duncan R: Drug-polymer conjugates: potential for improved chemotherapy. Anticancer Drugs 3: 175-210, 1992.

70. Kovar L, Strohalm J, Chytil P, et al: The same drug but a different mechanism of action: comparison of free doxorubicin with two different $\mathrm{N}$-(2-hydroxypropyl)methacrylamide copolymer-bound doxorubicin conjugates in EL-4 cancer cell line. Bioconjug Chem 18: 894-902, 2007.

71. Satchi R, Connors TA and Duncan R: PDEPT: polymer-directed enzyme prodrug therapy. I. HPMA copolymer-cathepsin B and PK1 as a model combination. Br J Cancer 85: 1070-1076, 2001.

72. Paul A, Vicent MJ and Duncan R: Using small-angle neutron scattering to study the solution conformation of $\mathrm{N}$-(2-hydroxypropyl)methacrylamide copolymer-doxorubicin conjugates Biomacromolecules 8: 1573-1579, 2007.
73. Pimm MV, Perkins AC, Strohalm J, Ulbrich K and Duncan R: Gamma scintigraphy of a ${ }^{123}$ I-labelled N-(2-hydroxypropyl) methacrylamide copolymer-doxorubicin conjugate containing galactosamine following intravenous administration to nude mice bearing hepatic human colon carcinoma. J Drug Target 3: 385-390, 1996

74. Duncan R, Seymour LC, Scarlett L, Lloyd JB, Rejmanova P and Kopecek J: Fate of N-(2-hydroxypropyl)methacrylamide copolymers with pendent galactosamine residues after intravenous administration to rats. Biochim Biophys Acta 880: 62-71, 1986.

75. Virgolini I, Muller C, Klepetko W, Angelberger P, Bergmann H, O'Grady $J$ and Sinzinger H: Decreased hepatic function in patients with hepatoma or liver metastasis monitored by a hepatocyte specific galactosylated radioligand. Br J Cancer 61: 937-941, 1990.

76. Schlepper-Schafer J, Hulsmann D, Djovkar A, Meyer HE, Herbertz L, Kolb H and Kolb-Bachofen V: Endocytosis via galactose receptors in vivo. Ligand size directs uptake by hepatocytes and/or liver macrophages. Exp Cell Res 165: 494-506, 1986.

77. Shiah JG, Dvorak M, Kopeckova P, Sun Y, Peterson CM and Kopecek J: Biodistribution and antitumour efficacy of long-circulating N-(2-hydroxypropyl)methacrylamide copolymer-doxorubicin conjugates in nude mice. Eur J Cancer 37 131-139, 2001.

78. Rihova B, Bilej M, Vetvicka V, Ulbrich K, Strohalm J, Kopecek J and Duncan R: Biocompatibility of N-(2-hydroxypropyl) methacrylamide copolymers containing adriamycin. Immunogenicity and effect on haematopoietic stem cells in bone marrow in vivo and mouse splenocytes and human peripheral blood lymphocytes in vitro. Biomaterials 10: 335-342, 1989.

79. Omelyanenko V, Kopeckova P, Gentry C, Shiah JG and Kopecek J: HPMA copolymer-anticancer drug-OV-TL16 antibody conjugates. 1. influence of the method of synthesis on the binding affinity to OVCAR-3 ovarian carcinoma cells in vitro. J Drug Target 3: 357-373, 1996.

80. Omelyanenko V, Gentry C, Kopeckova P and Kopecek J: HPMA copolymer-anticancer drug-OV-TL16 antibody conjugates. II. Processing in epithelial ovarian carcinoma cells in vitro. Int J Cancer 75: 600-608, 1998.

81. Kunath K, Kopeckova P, Minko T and Kopecek J: HPMA copolymer-anticancer drug-OV-TL16 antibody conjugates. 3 . The effect of free and polymer-bound adriamycin on the expression of some genes in the OVCAR-3 human ovarian carcinoma cell line. Eur J Pharm Biopharm 49: 11-15, 2000.

82. Jensen KD, Kopeckova P, Bridge JH and Kopecek J: The cytoplasmic escape and nuclear accumulation of endocytosed and microinjected HPMA copolymers and a basic kinetic study in Hep G2 cells. AAPS PharmSci 3: E32, 2001.

83. David A, Kopeckova P, Kopecek J and Rubinstein A: The role of galactose, lactose and galactose valency in the biorecognition of N-(2-hydroxypropyl)methacrylamide copolymers by human colon adenocarcinoma cells. Pharm Res 19: 1114-1122, 2002.

84. David A, Kopeckova P, Rubinstein A and Kopecek J: Enhanced biorecognition and internalization of HPMA copolymers containing multiple or multivalent carbohydrate side-chains by human hepatocarcinoma cells. Bioconjug Chem 12: 890-899, 2001.

85. Irimura T, Matsushita Y, Sutton RC, et al: Increased content of an endogenous lactose-binding lectin in human colorectal carcinoma progressed to metastatic stages. Cancer Res 51: 387-393, 1991.

86. Bresalier RS, Mazurek N, Sternberg LR, Byrd JC, Yunker CK, Nangia-Makker P and Raz A: Metastasis of human colon cancer is altered by modifying expression of the beta-galactosidebinding protein galectin 3. Gastroenterology 115: 287-296, 1998.

87. Ohannesian DW, Lotan D, Thomas P, Jessup JM, Fukuda M, Gabius HJ and Lotan R: Carcinoembryonic antigen and other glycoconjugates act as ligands for galectin-3 in human colon carcinoma cells. Cancer Res 55: 2191-2199, 1995

88. Lotz MM, Andrews CW Jr, Korzelius CA, Lee EC, Steele GD Jr, Clarke A and Mercurio AM: Decreased expression of Mac-2 (carbohydrate binding protein 35) and loss of its nuclear localization are associated with the neoplastic progression of colon carcinoma. Proc Natl Acad Sci USA 90: 3466-3470, 1993

89. Castronovo V, Campo E, van den Brule FA, et al: Inverse modulation of steady-state messenger RNA levels of two non-integrin laminin-binding proteins in human colon carcinoma. J Natl Cancer Inst 84: 1161-1169, 1992. 
90. David A, Kopeckova P, Minko T, Rubinstein A and Kopecek J: Design of a multivalent galactoside ligand for selective targeting of HPMA copolymer-doxorubicin conjugates to human colon cancer cells. Eur J Cancer 40: 148-157, 2004.

91. Etrych T, Strohalm J, Chytil P, Cernoch P, Starovoytova L, Pechar M and Ulbrich K: Biodegradable star HPMA polymer conjugates of doxorubicin for passive tumor targeting. Eur J Pharm Sci 42: 527-539, 2011.

92. Dvorak M, Kopeckova P and Kopecek J: High-molecular weight HPMA copolymer-adriamycin conjugates. J Control Release 60: 321-332, 1999.

93. Etrych T, Jelinkova M, Rihova B and Ulbrich K: New HPMA copolymers containing doxorubicin bound via $\mathrm{pH}$-sensitive linkage: synthesis and preliminary in vitro and in vivo biological properties. J Control Release 73: 89-102, 2001.

94. Schmid B, Chung DE, Warnecke A, Fichtner I and Kratz F: Albumin-binding prodrugs of camptothecin and doxorubicin with an Ala-Leu-Ala-Leu-linker that are cleaved by cathepsin B: synthesis and antitumor efficacy. Bioconjug Chem 18: 702-716, 2007.

95. Kratz F, Warnecke A, Scheuermann K, et al: Probing the cysteine-34 position of endogenous serum albumin with thiol-binding doxorubicin derivatives. Improved efficacy of an acid-sensitive doxorubicin derivative with specific albumin binding properties compared to that of the parent compound. J Med Chem 45: 5523-5533, 2002.

96. Warnecke A and Kratz F: Maleimide-oligo(ethylene glycol) derivatives of camptothecin as albumin-binding prodrugs: synthesis and antitumor efficacy. Bioconjug Chem 14: 377-387, 2003.

97. Kratz F and Beyer U: Serum proteins as drug carriers of anticancer agents: a review. Drug Deliv 5: 281-299, 1998.

98. Elzoghby AO, Samy WM and Elgindy NA: Albumin-based nanoparticles as potential controlled release drug delivery systems. J Control Release 157: 168-182, 2012.
99. Kratz F: Albumin as a drug carrier: design of prodrugs, drug conjugates and nanoparticles. J Control Release 132: 171-183, 2008.

100. Lebrecht D, Geist A, Ketelsen UP, Haberstroh J, Setzer B, Kratz F and Walker UA: The 6-maleimidocaproyl hydrazone derivative of doxorubicin (DOXO-EMCH) is superior to free doxorubicin with respect to cardiotoxicity and mitochondrial damage. Int J Cancer 120: 927-934, 2007.

101. Unger C, Haring B, Medinger M, Drevs J, Steinbild S, Kratz F and Mross K: Phase I and pharmacokinetic study of the (6-maleimidocaproyl)hydrazone derivative of doxorubicin. Clin Cancer Res 13: 4858-4866, 2007.

102. Dubowchik GM and Firestone RA: Cathepsin B-sensitive dipeptide prodrugs. 1. A model study of structural requirements for efficient release of doxorubicin. Bioorg Med Chem Lett 8: 3341-3346, 1998.

103. Dubowchik GM, Mosure K, Knipe JO and Firestone RA: Cathepsin B-sensitive dipeptide prodrugs. 2. Models of anticancer drugs paclitaxel (Taxol), mitomycin $\mathrm{C}$ and doxorubicin. Bioorg Med Chem Lett 8: 3347-3352, 1998.

104. Dubowchik GM,Firestone RA,PadillaL, et al: Cathepsin B-labile dipeptide linkers for lysosomal release of doxorubicin from internalizing immunoconjugates: model studies of enzymatic drug release and antigen-specific in vitro anticancer activity. Bioconjug Chem 13: 855-869, 2002

105. Calderón M, Quadir MA, Strumia M and Haag R: Functional dendritic polymer architectures as stimuli-responsive nanocarriers. Biochimie 92: 1242-1251, 2010.

106. De Groot FM, Broxterman HJ, Adams HP, et al: Design, synthesis and biological evaluation of a dual tumor-specific motive containing integrin-targeted plasmin-cleavable doxorubicin prodrug. Mol Cancer Ther 1: 901-911, 2002. 